\title{
Pediatric Idiopathic Venous Thrombosis
}

Gursev Sandlas*, Jyoti Bothra, Hemanshi Shah, Shallika Jayaswal

Department of Pediatric Surgery, TNMC \& BYL Nair Ch. Hospital, Mumbai, India

\begin{abstract}
Venous Thrombosis is a rare disorder of childhood. The scientific advances in neonatal and paediatric critical care has decreased neonatal mortality rate, however, it is associated with an increase in the incidence of complications which were rare, one such being venous thrombosis.
\end{abstract}

Keywords: Venous thrombosis; Idiopathic; Children

\section{Introduction}

Venous thrombosis is a rare pediatric disorder seen more often as a secondary complication to an unrelated primary disease process. An overwhelming majority are children surviving fatal disorders such as neonatal sepsis, congenital heart disease, tumours and trauma. Venous Thrombosis can also be seen as a complication to central venous catheterisation, congenital prothrombotic disorders etc. However, idiopathic Venous Thrombosis in children is still very rare. The present case is of an eighteen month old girl child who presented with features suggestive of lower limb cellulitis but was subsequently detected to have extensive deep venous thrombosis of the lower limb veins.

\section{Case Summary}

An eighteen month old girl child presented with complaints of fever since five days and sudden onset painful oedema of the right lower limb since one day. Examination of the patient revealed tender oedema of right lower limb from mid thigh to foot resembling cellulitis. In view of elevated leucocyte count with fever a probable diagnosis of cellulitis was made and patient was started on antibiotics. However despite a seemingly adequate therapy no improvement in patient status was seen over the subsequent 48 hours. An ultra sonogram with Duplex Colour Doppler of the lower limb was done which revealed a thrombus in the right popliteal vein. The patient was started on Low Molecular Weight Heparin in view of the extensive thrombus in the deep venous system. A follow up Doppler study after ten days of low molecular weight heparin therapy showed partial recanalization of the vein. Complete resolution of the thrombus was observed at the follow up study done after six months. Protein C, Protein S and Antithrombin III levels were normal. A 2-D echocardiogram of the heart showed a normal study. Patient is thriving well on follow up with no obvious post thrombotic sequelae.

\section{Discussion}

Contemporary thinking dictates that venous thrombosis is uncommon in children with an incidence of 0.07 per 10,000 children $[1,2]$.

Recent evidence of increase in the incidence can be partly attributed to heightened awareness and availability of sophisticated diagnostic techniques [1].

Unlike adults the incidence in children is linked to the age of the child $[3,4]$. Moreover decreased capacity to generate thrombin, increased levels of $\alpha 2$-macroglobulin to inhibit thrombin, and enhanced antithrombotic potential by the vessel wall preclude to a lower risk of development of Venous Thrombosis in children.

Central venous catheters are the single most important predisposing factor for the development of Venous Thrombosis in children [5]. However, idiopathic Venous Thrombosis is rarely seen and poorly reported in literature [6].

The clinical presentation varies with the site and extent of the thrombus and is usually presents as a tender, oedematous extremity with skin changes.

Doppler ultrasound is the gold standard investigation for diagnosis of Venous Thrombosis; however an insight into its inherent limitations is important. Chest CT and 2D-ECHO are needed to assess for other causes of Venous Thrombosis [7].

Unfractionated heparin, low-molecular-weight heparin and warfarin are the mainstay in anticoagulant therapy in pediatric patients [4]. However, due to low incidence and subsequent scarcity of data, no established well defined protocols exist for anticoagulation therapy in children. Pediatric patients present a unique challenge in the provision of anticoagulation. Much of the data that currently exists are from limited studies [8]. Recurrent Venous Thrombosis is usually related to the recurrence of risk factors or inadequate anti-coagulant therapy.

Post-Thrombotic Syndrome [PTS] is becoming more apparent in children with increased incidence of Pediatric Venous Thrombosis. It has an incidence of $60 \%$ covering about one third of the patient population $[9,10]$. Classical presentation being a tender, oedematous extremity with skin pigmentation and ulceration, PTS in children is usually mild and venous ulceration is seldom seen. Combined fibrinolytic and anticoagulation treatment decreases this incidence [11]. Venous Thrombosis related mortality being $1 \%$ to $2 \%[2,9,12]$.

Anticoagulant prophylaxis in children with CVCs is not yet recommended in absence of proven clinical relevance needing further evaluation. Prophylactic anticoagulation is useful for children with congenital thrombophilia and associated risk factors like trauma, surgery, severe infection and CVC [1].

\section{Conclusion}

Pediatric venous thrombosis is an enigma even to those treating

*Corresponding author: Dr. Gursev Sandlas , Assistant Professor, Departmen of Pediatric Surgery, TNMC \& BYL Nair Ch. Hospital, Mumbai Central, Mumbai 400008, India, Tel: 9320063398; E-mail:drgursev@gmail.com

Received June 09, 2014; Accepted August 20, 2014; Published August 22, 2014

Citation: Sandlas G, Bothra J, Shah H, Jayaswal S (2014) Pediatric Idiopathic Venous Thrombosis. J Vasc Med Surg 2: 153. doi: 10.4172/2329-6925.1000153

Copyright: @ 2014 Sandlas G, et al. This is an open-access article distributed under the terms of the Creative Commons Attribution License, which permits unrestricted use, distribution, and reproduction in any medium, provided the original author and source are credited. 
Citation: Sandlas G, Bothra J, Shah H, Jayaswal S (2014) Pediatric Idiopathic Venous Thrombosis. J Vasc Med Surg 2: 153. doi: 10.4172/23296925.1000153

Page 2 of 2

children. In view of the increasing incidence of venous thrombosis in children and its benign presentation it is axiomatic that we consider the presence of venous thrombus in any child presenting with cellulitis of the extremity not resolving with conventional therapy. Lack of sufficient data precludes to the general lack of awareness regarding appropriate management of this condition. Consensus regarding the anticoagulant therapy and associated protocols directed towards paediatric age group is the need of the hour.

\section{References}

1. Parasuraman S, Goldhaber SZ (2006) Venous thromboembolism in children Circulation 113: e12-16.

2. van Ommen $\mathrm{CH}$, Heijboer $\mathrm{H}$, Büller HR, Hirasing RA, Heijmans $\mathrm{HS}$, et al. (2001) Venous thromboembolism in childhood: a prospective two-year registry in The Netherlands. J Pediatr 139: 676-681.

3. Raffini L, Huang YS, Witmer C, Feudtner C (2009) Dramatic increase in venous thromboembolism in children's hospitals in the United States from 2001 to 2007. Pediatrics 124: 1001-1008.

4. Monagle P, Chan A, Massicotte P, Chalmers E, Michelson AD (2004) Antithrombotic therapy in children: the Seventh ACCP Conference on Antithrombotic and Thrombolytic Therapy. Chest 126: 645S-687S.

5. Sandoval JA, Sheehan MP, Stonerock CE, Shafique S, Rescorla FJ, et al. (2008) Incidence, risk factors, and treatment patterns for deep venous thrombosis in hospitalized children: an increasing population risk. J Vasc Surg. 47: $837-843$
6. Richardson MW, Allen GA, Monahan PE (2002) Thrombosis in children: current perspective and distinct challenges. Thromb Haemost 88: 900-911.

7. Male C, Kuhle S, Mitchell L (2003) Diagnosis of venous thromboembolism in children. Semin Thromb Hemost 29: 377-390.

8. Oschman A, Kuhn RJ (2010) Venous thromboembolism in the pediatric population. Orthopedics 33: 180-184.

9. Monagle P, Adams M, Mahoney M, Ali K, Barnard D, et al. (2000) Outcome of pediatric thromboembolic disease: a report from the Canadian Childhood Thrombophilia Registry. Pediatr Res 47: 763-766.

10. van Ommen $\mathrm{CH}$, Heijboer $\mathrm{H}$, van den Dool EJ, Hutten BA, Peters M (2003) Pediatric venous thromboembolic disease in one single center: congenital prothrombotic disorders and the clinical outcome. J Thromb Haemost 1: 25162522.

11. Manco-Johnson MJ, Nuss R, Hays T, Krupski W, Drose J, et al. (2000) Combined thrombolytic and anticoagulant therapy for venous thrombosis in children. J Pediatr 136: 446-453.

12. Gurgey A, Aslan D (2001) Outcome of noncatheter-related thrombosis in children: influence of underlying or coexisting factors. J Pediatr Hematol Oncol 23: $159-164$. 